\title{
SEGURANÇA NO TRABALHO EM AMBIENTES ESCOLARES DA EDUCAÇÃO PROFISSIONAL: UM CASO DO INSTITUTO FEDERAL
}

\author{
Helio Ricardo Duarte Portela1, Sergio Luiz Braga França² \\ Programa de Pós-graduação em Engenharia de Produção \\ Universidade Federal Fluminense \\ Rua Passo da Pátria, 156, sala 209 - São Domingos, Niterói - RJ - CEP: 24210-240
}

\begin{abstract}
RESUMO
O trabalho descreve um modelo de gestão de segurança e saúde no trabalho, possível de ser aplicado em ambientes escolares da educação profissional, de forma a integrar um SESMT, uma CIPA e um setor de psicologia do trabalho. Consideram-se, na formulação do modelo de gestão de segurança, não só os aspectos técnicos da melhoria de ambientes escolares tais como, máquinas, equipamentos e instalações, mas também aspectos que dizem respeito à saúde mental do corpo docente, discente e técnicos administrativos em educação. Trata-se de uma pesquisa bibliográfica com finalidade educativa. 0 modelo de gestão de segurança no trabalho mostrou-se adequado em caso de sua implementação no espaço da educação profissional.
\end{abstract}

Palavras-Chave: segurança do trabalho, gestão, SESMT, CIPA, psicologia do trabalho.

\begin{abstract}
This essay aims to describe a general model management safety and health at work, possible to be applied in professional education school settings, for that, it's possible to integrate an SESMT a CIPA and a psychology sector work. It's necessary to consider in the formulation of model safety management not only the technical aspects of improving school settings such as, machinery, equipment and facilities, but also aspects concerning the mental health faculty, student and technical administrators in education. The model management safety at work was adequate in the event of its implementation in the vocational education space.
\end{abstract}

Keywords: safety, management, SESMT, CIPA, work psychology.

\footnotetext{
${ }^{1}$ professor da educação professional, Mestre em Engenharia de Produção - Instituto Federal do Espírito Santo Campus Vitória. E-mail: heliop@ifes.edu.br

${ }^{2}$ professor da engenharia de produção, Doutor em Engenharia Civil - Universidade Federal Fluminense - Centro Tecnológico, Escola de Engenharia. E-mail: sergiofranca@gmail.com
} 


\section{INTRODUÇÃO}

A utilização de ferramentas de segurança tais como, análises preliminares de risco, mapas de risco, programas de prevenção de riscos ambientais, laudos de ergonomia, programas de controle médico da saúde ocupacional e procedimentos de segurança no trabalho, aplicados no contexto de um sistema de gerenciamento de riscos, representam a base para qualquer tipo de sistema de gestão em segurança e saúde ocupacional, visando à prevenção de acidentes do trabalho e ao melhoramento das suas condições de organização e planejamento.

As ferramentas de segurança geram procedimentos de segurança no trabalho capazes de disciplinar os atores escolares, entre os quais os professores, os alunos e também os técnicos administrativos em educação, no interior de ambientes escolares da Educação Profissional Tecnológica. Isso, porque é capaz de detectar as não conformidades em qualquer área de Risco Grave e Iminente às suas vidas. É também um grande fator de motivação para a mudança de comportamento, uma vez que todos passam a conhecer a quais agentes nocivos a sua saúde ocupacional está exposta. Visto que o corpo discente da instituição de educação profissional em estudo representa o produto final de todos os esforços dos docentes, vez que serão os futuros profissionais em áreas industriais, o autor desta pesquisa, que atua como docente de tal escola, na Área de Estudo Segurança do Trabalho, decidiu por descrever este Modelo de Gestão de Segurança no Trabalho para que seja discutido e implantado. Com a implantação deste modelo, poderemos disciplinar os alunos a seguirem os mesmos exemplos, quando estiverem na condição de profissionais em empresas, pois, com eles já estrão ambientados na instituição de ensino. Segundo a Seção IV do Equipamento de Proteção Individual (EPI) da Lei 6514, de 22 de dezembro de 1977, em seu Art. 166:

Art. 166: A empresa é obrigada a fornecer aos empregados, gratuitamente, Equipamento de Proteção Individual (EPI), adequado ao risco e em perfeito estado de conservação e funcionamento, sempre que as medidas de ordem geral não ofereçam completa proteção contra os riscos de acidentes e danos à saúde dos empregados. 
O trabalho descreve, também, a situação da segurança no trabalho aplicada no interior de ambientes escolares, por intermédio da descrição das experiências com segurança, já implantadas, com sucesso, em algumas prestigiadas instituições federais de ensino. A partir da descrição destes fatos reais, descreve-se a estrutura de um modelo de gestão de segurança no trabalho para implantação em ambientes escolares da educação profissional, contemplando SESMT, CIPA e psicologia do trabalho.

Os profissionais do Serviço Especializado em Engenharia de Segurança e em Medicina do Trabalho (SESMT) devem procurar influenciar e alterar o sistema produtivo de forma lenta e gradativa, bem como trabalhar em parceria com todos os níveis organizacionais. Os riscos no trabalho deixaram de ser apenas de aspecto técnico, passando a se configurar também por sua natureza ética e política, influenciado pelo poder da sociedade sobre as empresas (PORTO, 2000).

Quando não são fatais, os acidentes geralmente têm como resultado nas mais variadas lesões corporais, como ferimentos, contusões, escoriações, entorses, fraturas, queimaduras etc., podendo causar prejuízos de diversas ordens, quais sejam, de produção e de ordem social e econômica (MACHADO e SOUZA, 1980). As doenças profissionais representam um sério obstáculo para a produtividade e para a eficiência do trabalho e devem despertar as empresas no sentido de tomarem medidas visando a melhorar o estado de saúde dos trabalhadores. Combater fatores existentes no processo produtivo, como os riscos físicos, químicos, biológicos, de acidentes e ergonômicos torna-se essencial para minimizar esses problemas profissionais.

\section{UM BREVE HISTÓRICO}

\subsection{A Instituição de Ensino Estudada}

A Instituição de Ensino em estudo foi criada em 23 de setembro de 1909. Foi regulamentada pelo Decreto 9.070 de 25 de outubro de 1910. Nesta época formava profissionais Artesãos. A partir de 1937, a Instituição passou a formar Profissionais voltados para a Produção. Em 11 de dezembro de 1942, foi inaugurado o prédio onde funciona até hoje. Na época contava com 
Internato e Externato, oficinas e salas de Aula. Atendia aos cursos de artes de couro, alfaiataria, marcenaria, serralheria e mecânica. Em de setembro de 1965, passou a funcionar baseada num modelo empresarial. Em 2004, a Instituição de Ensino passou a oferecer educação superior.

\subsection{Segurança e Saúde Ocupacional em Ambientes Escolares}

A escola deve se prevenir quanto às situações de risco para os alunos e manter-se atenta ao acompanhamento deles. Isso, com o objetivo de evitar acidentes e outras situações de perigo para a comunidade escolar. É importante que os profissionais da educação tenham acesso às informações sobre os principais acidentes, como evitá-los e como agir diante das situações que exijam cuidados imediatos. Os docentes também devem promover projetos ou ações escolares de modo a provocar mudanças no comportamento dos alunos em relação à prevenção de acidentes. Nesse sentido já existem algumas iniciativas.

Na cidade de São Paulo, há um projeto de prevenção de acidentes e primeiros socorros nas escolas municipais. No estado de São Paulo, existe um projeto de Lei no 595/2006 que autorizaria o Poder Executivo a criar o Programa de Prevenção de Acidentes nas Escolas Públicas do Estado de São Paulo, por meio da instalação de Comissões Internas de Prevenção de Acidentes e Violência Escolar. Em Maceió, a Sociedade Alagoana de Pediatria, encaminhou um projeto de lei à câmara municipal da cidade e, em 2002, foi sancionada a lei que cria o Programa de Prevenção de Acidentes e Violência nas Escolas Públicas da cidade de Maceió.

Em 2008, a Lei no 6.993 é criada, o que autoriza o Estado de Alagoas a criar o Programa de Prevenção de Acidentes nas Escolas Públicas no Estado. Diversas instituições de ensino passam a se preocupar com essa temática. O SENAI, por exemplo, por ser uma instituição tradicional de formação técnica, possui um compromisso muito forte com a segurança dos seus alunos, tanto dentro da instituição quanto na preparação para o exercício profissional. No manual do aluno do SENAI, na sessão de deveres dos alunos, constam algumas regras relacionadas à prevenção de acidentes. 
O Instituto Federal Mineiro, Campus Bambuí, faz um trabalho de qualidade quanto à segurança dos seus funcionários e alunos, contando com uma Comissão Interna de Prevenção de Acidentes (CIPA). A comissão criou um Portal onde todos servidores, colaboradores e público externo podem participar da gestão da CIPA e acompanhar o trabalho desenvolvido por eles. No portal, é possível acessar as legislações (Normas regulamentadoras), o manual da CIPA, o Programa de Controle Médico e Saúde Ocupacional (PCMSO) e o Plano de Prevenção de Riscos Ambientais (PPRA). Outros Institutos Federais possuem iniciativas quanto à prevenção de acidente dentro de suas instalações com a formação de CIPA, mas não socializam informações suficientes nas suas páginas na internet. 0 Instituto Federal de Sergipe é um exemplo. É muito pequena a quantidade de Institutos que se preocupam com a segurança de seus alunos e funcionários, pois, à época da criação dos Institutos, havia 168 unidades espalhadas pelo Brasil.

Outro trabalho que merece ser citado é o da UNIDAVI em Santa Catarina. A instituição possui um portal com todas as ações da CIPA, informações sobre os objetivos, a agenda, as atas e ainda veicula fotos e o texto da NR-5. Além disso, cada Campus da Instituição possui um Mapa de Riscos, que pode ser acessado no portal. Outras Faculdades e Universidades também se preocupam com essa temática, criando CIPA. A Comissão Interna de Prevenção de Acidentes do IFSC - INSTITUTO DE FÍSICA DE SÃO CARLOS vem zelando pela segurança e o bem-estar dos funcionários no ambiente de trabalho. Tal preocupação se traduz em diversas iniciativas que procuram diminuir o risco de acidentes e a ocorrência de doenças ocupacionais aos seus funcionários. Nos últimos anos, por exemplo, além das ações de caráter contínuo como vistoria, atualização de mapas de riscos, aquisição de Equipamentos de Proteção Coletiva, a CIPA do IFSC intensificou a comunicação entre os funcionários por meio de seus representantes, afixando cartazes contendo os nomes, telefones e e-mails dos membros da comissão e principalmente atuação através de contato corpo a corpo.

A CIPA do IFSC participa intensamente da SIPAT - Semana Interna de Prevenção de Acidentes, realizada conjuntamente com as Unidades do Campus USP de São Carlos, além de eventos em parceria com o SESMT local, quando são promovidos cursos teóricos e práticos, seminários, palestras que contribuem para a redução de custos e geração de recursos. O IFSC, ao promover a segurança e o bem-estar do funcionário, acaba fazendo dele um trabalhador mais 
produtivo, bem como diminui sensivelmente o número de afastamentos médicos por acidente de trabalho. É a valorização dos recursos humanos gerando mais recursos ou, no mínimo, mantendo os existentes.

A cultura de segurança e medicina do trabalho avançou bastante, com ações concretas que demonstram vontade política inédita na UNICAMP. É o próprio Sindicato dos trabalhadores da UNICAMP que reconhece: Foram criados o Programa de Prevenção de Riscos Ambientais, montagem do Comitê de Higiene e Segurança do Trabalho, mapa de riscos,exames periódicos, etc." (Boletim do STU, 25/01/2001, p. 4.)Pelo menos 18 ações mudaram o rumo da área na UNICAMP e envolveram o trabalho conjunto de órgãos como o CECOM, Prefeitura do Campus, SESMT/DGRH, CEMEQ, entre outros. A Prefeitura do Campus iniciou um plano para submeter a controle a ação de empreiteiras e terceirizadas no âmbito da Universidade. Peça fundamental nesta ação, a Prefeitura do Campus criou uma série de mecanismos de controle e implementou uma subseção do Serviço de Segurança e Medicina do Trabalho - SESMT, no interior do órgão contando com uma Engenheira de Segurança especializada e um técnico de segurança. É visível a melhoria da segurança nos canteiros de obra e no controle de terceirizadas no interior da Universidade. Paralelamente a isto, no campo da saúde ocupacional a Prefeitura, com apoio da DGRH e do CECOM, conduz atualmente um plano de caracterização de fontes de lesão (LER-DORT) e alteração de condições de trabalho, bem como de ação assistencial e corretiva com os servidores daquele órgão. A UNICAMP retomou com decisão a realização de exames previstos em lei, em especial os exames periódicos. Nesta matéria, pretende ir além das determinações legais não distinguindo entre servidores estatutários e celetistas. O CECOM e a Medicina do Trabalho atuaram decididamente e pela primeira vez todos os celetistas (e opcionalmente os estatutários que desejaram) fecharam o ano de 2000 com todos os seus exames em dia. Além disso, os médicos do trabalho foram alocados especificamente nas áreas da Universidade identificando, portanto, a responsabilidade de cada um, perante um definido conjunto de usuários. Isso permitiu maior atenção e continuidade do acompanhamento dos servidores e de sua situação ocupacional. Como atestam as ações realizadas, os últimos dois anos significaram para a UNICAMP um amadurecimento e conscientização da necessidade de se empreender um grande plano para colocar a segurança e a medicina do trabalho em um outro patamar. 
A Saúde e Segurança no Trabalho é fundamental para que o país cresça e demonstre o seu potencial consolidado em um desenvolvimento com ética, e o Sesi trabalha para isso. O SenaiRS preocupa-se com a saúde e segurança dos alunos que amanhã estarão nas empresas. Os conceitos e o desenvolvimento da cultura preventiva são trabalhados com os alunos para que eles os disseminem. Os casos envolvendo acidente com alunos, dentro de Instituições de Ensino, tanto públicas como privadas, são tratados com base no art.14 do Código de Defesa do Consumidor, pois existe uma relação de consumo, portanto existe responsabilidade objetiva, ou seja, existe a obrigação de indenizar mesmo que o estabelecimento de ensino não seja o culpado pelo acidente.

O contexto atual de globalização, competitividade entre mercados e crescente sensibilização da sociedade em reconhecer a responsabilidade social e ambiental, como um valor permanente, tem contribuído para que muitas empresas percebam as vantagens competitivas em investir na melhoria da Gestão de Segurança, Meio Ambiente e Saúde.

De acordo com Slack (1997, apud ESTEVES, 2004),

para uma empresa se manter competitiva no atual ambiente, deve possuir características, que nada mais são que seus objetivos de desempenho, quais sejam, qualidade, rapidez, flexibilidade, produtividade, preço competitivo e confiabilidade. 0 respeito ao meio ambiente e a segurança de processo vem sendo também características cada vez mais exigidas não só por legislações como também pela opinião pública.

Estas características não são excludentes, devem estar, portanto presentes ao mesmo tempo, e a falta de uma delas acarreta baixo desempenho global da empresa, podendo até levá-la ao fracasso de sua missão ficando excluída do atual ambiente competitivo.

\section{A IMPORTÂNCIA DO SESMT E DA CIPA NAS ORGANIZAÇõES}

Segundo Moraes (2004), ao iniciar um trabalho em uma organização, é fundamental identificar os diferentes grupos sociais existentes para que seja possível desempenhar, de forma consistente, as atribuições de segurança, meio ambiente e saúde. Essa percepção é imprescindível para avaliar como as pessoas entendem o trabalho dos profissionais de 
segurança, meio ambiente e saúde, bem como também, o valor dado a este trabalho. Os Profissionais de Segurança eram nomeados ou se ofereciam para exercer atividades relacionadas com a Segurança Ocupacional. Existiam muitas dúvidas se estes profissionais, sem uma formação específica, seriam capazes, tecnicamente, de atuar e assumir responsabilidades que exigiam conhecimentos específicos nas áreas de Engenharia e Medicina do Trabalho.

Com a evolução do nível de responsabilidade e da cultura de SMS passou a existir um entendimento de que os Profissionais do SESMT e da CIPA não são os únicos responsáveis pelas ações de Segurança dentro de uma Organização. Grandes organizações, como a PETROBRÁS, por exemplo, criaram os facilitadores de SMS, Profissionais com formação e experiência em diversas áreas, direcionados para auxiliar os Profissionais do SESMT e da CIPA no processo de organização e implementação do Sistema de Gestão. A adoção de um sistema de gestão da segurança e saúde no trabalho permite não só atender às exigências sociais, mas incorporar, nessa iniciativa, o atendimento às Legislações Trabalhistas, a eliminação ou redução dos custos financeiros, com os encargos provenientes dos incidentes funcionais, e o bem-estar funcional dos trabalhadores.

No mundo atual, a quantidade e potencialidade dos riscos, que podem recair sobre a empresa, adquiriram um valor substancial que tornam imperativa a sua minimização, concorrendo, para isto, inúmeros fatores, dos quais se destacam:

- Investimento elevado em equipamento mais sofisticado.

- Investimento elevado aplicado em novas fontes de energias mais perigosas.

- Novos processos tecnológicos de fabricação, sem controle total do processo.

- Meios de transportes mais perigosos.

Do ponto de vista do capital, a dimensão ontológica do trabalho é subsumida à dimensão produtiva, pois, nas relações capitalistas, o sujeito é o capital e o homem é o objeto. Assim, assumir o trabalho como princípio educativo na perspectiva do trabalhador, como diz Frigotto, 
implica superar a visão utilitarista, reducionista de trabalho. Implica inverter a relação, situando o homem e todos os homens como sujeitos do seu devir. Esse é um processo coletivo, organizado, de busca prática de transformação das relações sociais desumanizadoras e, portanto, deseducativas. A consciência crítica é o primeiro elemento deste processo que permite perceber que é dentro destas velhas e adversas relações sociais que podemos construir outras relações, nas quais o trabalho se torne manifestação de vida e, portanto, educativo" (FRIGOTTO, 1989, p.8).

A cultura de Gerenciamento de Risco deve estar enraizada em cada nível da empresa, a começar pelos cargos mais altos. Isto posto, segue abaixo um Modelo de Gerenciamento de Risco que poderá ser aplicado a qualquer tipo de Empresa e em qualquer Atividade Econômica.

\section{CONSIDERAÇÕES FINAIS}

\subsection{Proposta de Gestão de Segurança do Trabalho}

Uma Gestão de Segurança do trabalho deve contemplar como meta a manutenção da Saúde Mental e Bem estar do Trabalhador nos ambientes de trabalho, pois este é o foco inicial que deverá ser atacado quando se deseja fazer Prevenção e alcançar a meta de um ambiente de trabalho sem estresse, estressores e acidentes do trabalho. Para isto, será necessário que, além da presença de profissionais de Segurança do Trabalho de acordo com o preconizado e exigido pela NR-04 - SESMT ( portaria 3214, de 8 de junho de 1978 - MTE ) e da implantação de uma CIPA conforme a NR-05 (Portaria 3214, de 8 de junho de 1978 - MTE ), haja a presença de um profissional Psicólogo do Trabalho inserido no SESMT. Com este profissional será possível a análise e o estudo do trabalhador no que se refere a sua saúde mental com maior nível de complexidade e realidade.

O próximo passo será a criação de um Cadastro Social de Trabalhadores, com informações repassadas aos profissionais do SESMT pelos próprios trabalhadores, a saber:

- Perfis psicossociais, educacionais e econômicos dos trabalhadores. 
- Nível de satisfação de cada trabalhador com o seu posto de trabalho.

- Nível de satisfação de cada trabalhador com relação à sua empresa.

- Nível de satisfação dos trabalhadores com o ambiente de trabalho.

- Nível de satisfação dos trabalhadores com relação às condições de segurança do

- trabalho e saúde ocupacional em sua empresa.

- Nível de satisfação dos trabalha dores com relação ao modo de gestão da empresa.

- Principais agentes estressores dos ambientes de trabalho.

\subsection{Responsabilidades}

O Gerenciamento de riscos ambientais para que funcione de forma eficaz deverá ter um Serviço Especializado em Engenharia de Segurança e em Medicina (SESMT) do trabalho, dividido em 03 (três) setores, a saber:

- Engenharia do Trabalho: composto pelos profissionais Engenheiro de segurança do Trabalho e Técnico de Segurança do Trabalho.

- Medicina do Trabalho: composto pelos profissionais Médico do Trabalho; Enfermeiro do Trabalho e Auxiliar de Enfermagem do Trabalho.

- Psicologia do Trabalho: composto pelo profissional Psicólogo do Trabalho.

O setor de Engenharia do Trabalho será responsável pelas seguintes atribuições:

- Realização de PPRA, PCMAT, PGR, LTCAT, PCA, PPR, Laudos de Ergonomia, CAT, Divulgação dos Procedimentos de Segurança em todos os Níveis hierárquicos, Treinamentos (com empregados próprios e terceirizados), Palestras, SIPAT, Programas Educacionais relacionados a saúde do trabalhador.

- Inspeções em Postos e Ambientes de Trabalho.

- Avaliações Qualitativas de Riscos ambientais do Trabalho.

- Avaliações Quantitativas de Riscos Ambientais.

- Controle e Monitoramento dos Riscos.

- Projetos e implantação de EPC. 
- Prescrição do EPI por Função do Trabalhador e repassar os dados ao Setor de Almoxarifado para que os mesmos sejam distribuídos aos Trabalhadores.

- Projetos de Mudanças e Melhorias de Máquinas, Equipamentos e Lay-Out dos ambientes de trabalho.

- Participação em Reuniões de CIPEIROS.

- Elaboração de PPP juntamente com a Medicina do Trabalho.

- Elaboração de Relatórios Técnicos sobre ambientes de Trabalhos.

- Agendamento de reuniões periodicas com o setor de Medicina do Trabalho, Psicologia do Trabalho e com a CIPA, visando a troca de informações e a discussão de problemas comuns de todo o processo de Gerenciamento de Riscos.

O setor de Medicina do Trabalho será responsável pelas seguintes Atribuições:

- Realização de todos os exames (admissionais, periódicos, mudança de função, retorno ao trabalho, admissional).

- Realização do documento PPP em conjunto com a engenharia do trabalho.

- Realização do PCMSO.

- Orientação quanto à definição da composição dos postos de trabalho com relação as variáveis trabalhador $\mathrm{x}$ função de acordo com os resultados da saúde do trabalhador verificados no PPP.

- Reunião periódica com o setor de engenharia do trabalho, psicologia do trabalho e com a CIPA, visando à troca de informações e à discussão de problemas comuns de todo o processo de gerenciamento de riscos.

- Identificação, em seu início, de possíveis anomalias na condição da saúde dos trabalhadores que possam vir a intervir de forma negativa no seu desempenho diário.

- Verificação acerca da necessidade de mudar algum trabalhador de posto de trabalho.

O setor de Psicologia do Trabalho será responsável pelas seguintes Atribuições:

- Elaboração do cadastro social dos trabalhadores, contendo os perfis socioeconômicos dos mesmos e os agentes estressores do ambiente de trabalho, com base em 
informações dos próprios trabalhadores, bem como suas consequências para os ambientes de trabalho e saúde mental.

- Reconhecimento de imediato e de forma preventiva dos principais geradores, causas e postos de trabalho de onde se origina a maior parte do estresse laboral a fim de prevenir acidentes do trabalho.

- Reuniões periódicas com o setor de engenharia do trabalho, medicina do trabalho e com a CIPA, visando à troca de informações e à discussão de problemas comuns de todo o processo de gerenciamento de riscos.

Baseado então nas conclusões dos dados apresentados pelos Profissionais da Engenharia do trabalho, Medicina do trabalho, Psicologia do Trabalho e também provenientes das Reuniões de Cipeiros, serão marcadas reuniões periódicas com as altas Chefias Imediatas das áreas de trabalho, a saber:

- Representante do empregador (presidente da CIPA).

- Representante dos trabalha dores (vice-presidente da CIPA).

- Representante da engenharia do trabalho (engenheiro de segurança do trabalho).

- Representante da medicina do trabalho (médico do trabalho).

- Representante da psicologia do trabalho (psicólogo do trabalho).

Do resultado final destas reuniões, deverão sair todas as soluções que visem a melhorias nos ambientes de trabalho, bem como informações precisas da medicina do trabalho e da psicologia do trabalho com relação a aspectos socioeconômicos e psíquicos, relacionados à saúde mental dos trabalhadores. 0 principal responsável pela implementação dos programas de segurança e saúde ocupacional deverá ser o presidente da empresa, seu principal preposto.

\subsection{Equipes de emergência}

O programa de gerenciamento de riscos deverá contemplar também equipes de emergência (composta de funcionários com vínculo empregatício), formadas e treinadas pelos profissionais da engenharia do trabalho com a responsabilidade de enfrentar situações de emergência ou iminência de acidente. 
Estas equipes de emergência poderão salvaguardar o Patrimônio da Empresa, em casos de incêndio, servindo como Brigadas de Incêndio e até salvar vidas humanas. 0 responsável pela equipe de emergência deve estar familiarizado com todos os processos, conhecendo as instalações, os respectivos riscos e os sistemas de proteção.

\subsection{Auditoria e atualização periódica}

Periodicamente todo o Sistema de Gerenciamento de Riscos deverá ser Auditado e verificado se tudo quanto foi planejado está sendo executado por todos os Profissionais responsáveis, em todas as suas etapas. Por meio de uma auditoria eficiente, pode se definir se um Programa de Gerenciamento de Riscos está ou não evoluindo com o tempo.

É necessária a introdução de um modo de gestão de riscos participativo na escola, visando principalmente à colaboração e ao envolvimento de todos os trabalhadores dos diferentes níveis hierárquicos, delegando-lhes responsabilidades e autonomia no envio de sugestões para a resolução dos problemas técnicos dos ambientes de trabalho e de todo o processo de produção a fim de se melhorarem as condições de trabalho. 0 saber e o conhecimento empírico dos trabalhadores sobre os riscos do trabalho devem ser respeitados, quando da busca de soluções para os problemas, pois, a saúde pertence ao próprio trabalhador (OLIVEIRA e VASCONCELLOS, 2000). Desta maneira, o trabalhador, o maior conhecedor dos ambientes de trabalho, se sentirá mais importante e sentindo-se parte de um todo do Programa de Gerenciamento de Riscos, o que fará com que o seu envolvimento e motivação para as mudanças sejam maiores.

0 gerenciamento dos riscos deve contemplar ordens e procedimentos que façam com que o trabalhador tenha a percepção de que ele mesmo participou de forma decisiva daquelas prescrições e normalizações. É essencial que isto seja considerado, antes de procurar responsabilizar o trabalhador por um acidente ou por uma infração à norma. (NOUROUDINE, 2004). 
É necessário, portanto, buscar uma análise global e conjunta com a participação de trabalhadores e empresários, baseada na união do saber técnico com o saber empírico de todos os sujeitos envolvidos no processo produtivo. Só desta maneira teremos uma nova Representação do Trabalho com destaque para um enfoque participativo.

\section{REFERÊNCIAS}

ARAUJO, Giovanni Moraes de. Legislação de segurança e saúde ocupacional : Normas Regulamentadoras do Ministério do Trabalho e Emprego. 2. ed. Rev. Ampl. e Atual. Rio de Janeiro: Gerenciamento Verde Consultoria Editora, 2008.

BRASIL, Luiz Augusto Damasceno. (org.). Dicas de prevenção de acidentes e doenças no trabalho: SESI-SEBRAE Saúde e Segurança no Trabalho: micro e pequenas empresas. Brasília: SESI-DN, 2005.

CAMPOS, José Luiz Dias; CAMPOS, Adelina Bitelli Dias. Acidentes do trabalho: prevenção e reparação. 3. ed. São Paulo: LTr, 1996. 488 p.

CIAVATTA FRANCO, Maria. O trabalho como princípio educativo da criança e do adolescente. Tecnologia Educacional, ABT, Rio de Janeiro, 21 (105/106): 25-29, mar./jun. 1992.

DUQUE, Ricardo, H. M. Mudança de cultura de segurança do trabalho: estudo de caso em obra de construção e montagem em uma refinaria de petróleo. 2005. Dissertação (Mestrado em Sistemas de Gestão). Programa de Pós-Graduação em Sistema de Gestão em Segurança do Trabalho da Universidade Federal Fluminense, Niterói, 2005.

ESTEVES, Alan S. Gerenciamento de riscos em planta de processos petroquímicos básicos : uma proposta de metodologia estruturada. 2004. Dissertação (Mestrado em Siste mas de Gestão) - Programa de Pós-Graduação em Sistemas de Gestão em Segurança do Trabalho, Universidade Federal Fluminense, Niterói, 2004.

FANTAZZINI Mário; CICCO, Francesco de. Introdução à Engenharia de Segurança de Sistemas. 3. ed. São Paulo: Fundacentro, 1993. 109 p.

FREITAS, Carlos Machado de; POR TO, Marcelo Firpo de Souza ; MACHADO, Jorge Mesquita Huet. (Orgs.). Acidentes industriais ampliados: desafios e perspectivas para o controle e a prevenção. Rio de Janeiro: Fiocruz, 2000. 321 p. 
FRIGOTTO, Gaudêncio. É falsa a concepção de que o trabalho dignifica o homem. Entrevista. Comunicação, Belém, 7 de agosto de 1980.

MACHADO, C.C.; SOUZA, A.P. Segurança no trabalho com motosserras. Viçosa, MG: UFV, 1980. 10 p. (Boletim de Extensão, 21).

MACHADO, Jorge Mesquita Huet. (Orgs.). Acidentes industriais ampliados: desafios e perspectivas para o controle e a prevenção. Rio de Janeiro: Fiocruz, 2000. 321 p.

Manual de Legislação Atlas. Segurança e Medicina do Trabalho. Ministério do Trabalho, 2010

NOUROUDINE, A. Risco e atividades humanas: acerca da possível positividade aí presente. FIGUEIREDO, M., ATHAYDE, M., BRITO, J. \& ALVA REZ, D. (org.) Labirintos do Trabalho: interrogações e olhares sobre o trabalho vivo. Rio de Janeiro: DP\&A Editora, 2004.

OLIVEIRA, M. H. Barros de; VASCONCELLOS, L. C. Fadel de. As políticas públicas brasileiras de saúde do trabalhador: tempos de avaliação. Saúde em Debate, v. 24, n.5, p. 92-103, 2000.

QUELHAS, Adriane D. Desenvolvimento de uma cultura de segurança total: o caso de indústria automotiva na região sul fluminense. 2006. 123fs. Dissertação (Mestrado em Sistemas de Gestão). Programa de Pós-Graduação em Sistema de Gestão em Segurança do Trabalho, Universidade Federal Fluminense, Niterói, 2006.

RAMOS, Marise Nogueira. 0 projeto unitário de ensino médio sob os princípios do trabalho, da ciência e da cultura. FRIGOTTO, Gaudêncio e CIAVATTA, Maria (org.). Ensino médio. Ciência, cultura e trabalho. Brasília, MEC.SEMTEC, 2004.

REGO, Márcio A. M. Metodologia qualitativa de gestão de riscos operacionais de segurança, meio ambiente e saúde ocupacional: uma contribuição ao Programa de Segurança de Processos. 20f. 2005.

ROBOREDO, Maria Lúcia Freire. Da segurança e da medicina do trabalho e a Constituição federal de 1988. Rio de Janeiro: Liber Juris, 1992. 246 p.

VIANNA, Héder Alencar.1967. Proposta de um sistema de gestão da segurança e saúde 2007 no trabalho, no campus da Universidade Federal de Viçosa, com ênfase no setor florestal. Viçosa, MG, 2007

WISNER, Alain. A inteligência no trabalho: textos selecionados de ergonomia. São Paulo: FUNDACENTRO, 1994. $190 \mathrm{p}$. 